\title{
A Global Pandemic Is Not Our Only Challenge in Urology
}

\author{
Peter Black, Editor-in-Chief $\bowtie$ \\ Soc Int Urol J. 2021;2(1):5-6
}

Rarely has the transition from one year to the next been so eagerly anticipated as when we said goodbye (and good riddance!) to 2020 and ushered in 2021. We all would like a return to our "old" lives as they were in 2019. The launch of global vaccination programs against the SARS-CoV-2 virus makes the light at the end of the tunnel clearly visible.

COVID-19, however, has not prevented us from addressing some important challenges in urology, including the issue of gender inequality, which is more prevalent in urology than in any other medical specialty. Less than $10 \%$ of urologists in the US are women, compared with $50 \%$ of pediatricians and obstetriciangynecologists [1-3]. This number has increased over time, and the fact that approximately one third of applicants to the US and Canadian urology residency matches are female indicates that these numbers are on the rise. The ultimate goal of gender equality is to develop a diverse urologic workforce that provides optimal patient care[4].

Since approximately one half of medical students are female[5], there is no question that the most imperative objective is to attract more talented female medical students into urology training programs. This goes beyond simply overcoming misconceptions about urologists dealing strictly with prostates and the male genitalia. Providing role models and mentorship for female medical students considering their career options is critical for enhancing female representation in urology. This is equally critical for inspiring young women in urology to seek academic and leadership positions.

There have been some notable achievements of women in urology in 2020, each of which is linked to an outstanding role model in the field. The most prestigious awards for early career urologists in the US (the American Urological Association Gold Cystoscope Award[6]) and in Europe (the European Association of Urology Crystal Matula Award) both went to remarkable women: Stacy Loeb and Derya Tilki, respectively. It is noteworthy that both have research and clinical expertise in prostate cancer, which emphasizes that women in urology should not be cornered into a focus on pediatric or female urology, as has often happened in the past. The gender gap in urologic oncology has been particularly stark, but this year two major awards of the Society of Urologic Oncology in the US were given to women who are real trailblazers in the field: the Huggins Medal to Eila Skinner[7], and the Young Investigator Award to Angela Smith[8]. These are just a handful of examples of women in urology being recognized for their outstanding achievements and contributions. They offer grounds for optimism that we are slowly overcoming some of the gender barriers.

These signs of progress in addressing the gender gap in urology are all from North America and to a lesser degree Europe. We know much less about the relative numbers of women in urology in the rest of the world, but it is likely the gender gap remains a much bigger issue, especially in low- and medium-income countries . For example, the organization Women in Surgery Africa reports that 7\% of practicing surgeons in the College of Surgeons of East Central and Southern Africa region are women.

The SIU is a global organization with global representation well beyond North America and Europe. Racial and ethnic diversity are the very fabric of the organization, but addressing gender disparity remains a challenge. The Board of Directors of the SIU has recognized gender equality as a priority. Two members of the current Board are women, and the organization continues to work towards full representation.

As we build our new journal, the SIUJ, we also need to be particularly cognizant of female representation. A glance across the editorial boards of leading urological journals around the world would suggest that we all need to be much better in this regard. Are journal editorial boards the last bastion of the "old boys club" in urology? This question is posed not as a criticism of other journals, but as a call to action for us all to improve representation of women in the editorial process in urology. These are important leadership positions that shape our field. An effort to increase female representation now should lead to equality in the future.

The core editorial group at SIUJ has made it a priority to tackle the gender gap. We are not necessarily experts in this mission, so missteps are likely-but we intend to be flexible and responsive, and we welcome input from all stakeholders. We are faced with the added challenge 
of requiring global representation as a top priority for the SIUJ yet having few women in urology in many of the global urologic communities. This, however, can be viewed not as a limitation but as an opportunity. It allows the SIUJ to contribute to breaking down barriers.

\section{References}

1. Medscape Physician Compensation Report 2015. Available at: https://www.medscape.com/slideshow/compensation-2015overview-6006679. Accessed December 18, 2020.

2. Ilin J, Langlois E, Jalal S, Khosa F. Gender disparity within academic Canadian urology. Can Urol Assoc J. 2020 Apr;14(4):106-110. doi: 10.5489/cuaj.6117. Epub 2019 0ct 28.

3. American Urological Association. The state of urology workforce and practice in the United States 2017. 2018. Available at: https:// www.AUAnet.org/common/pdf/research/census/State-UrologyWorkforce-Practice-US.pdf. Accessed June 22, 2018.

4. Meara JG, Leather AJM, Hagander L, Alkire BC, Alonso N, Ameh EA, et al. Global Surgery 2030: evidence and solutions for achieving health, welfare, and economic development. Lancet. 2015 Aug 8;386(9993):569-624. PMID: 25924834 DOI: 10.1016/S01406736(15)60160-X. Epub 2015 Apr 26.

5. Association of American Medical Colleges. More women than men are enrolled in medical school. https://www.aamc.org/ news-insights/more-women-men-are-enrolled-medical-school
Ultimately, we all aim for a global urology community in which gender equality is a given and not something we need to think about and promote. For now, however, there is a lot of work to be done.

6. The American Urological Association Gold Cystoscope Award. 2021 Award Winners. Available at: https://www.auanet.org/about-us/ aua-governance/awards/award-winners. Accessed December 18, 2020.

7. Society of Urologic Oncology Inc. The Huggins Medal. Available at: https://suonet.org/awards/huggins-medal.aspx. Accessed December 18, 2020.

8. Society of Urologic Oncology Inc. The Young Investigator Award. Available at: https://suonet.org/awards/young-investigator-award. aspx. Accessed December 18, 2020.

9. Xepoleas MD, Munabi NCO, Auslander A, Magee WP, Yao CA. The experiences of female surgeons around the world: a scoping review. Review Hum Resour Health. 2020 Oct 28;18(1):80. doi: 10.1186/ s12960-020-00526-3. PMID: 33115509 PMCID: PMC7594298 DOI: 10.1186/s12960-020-00526-3 